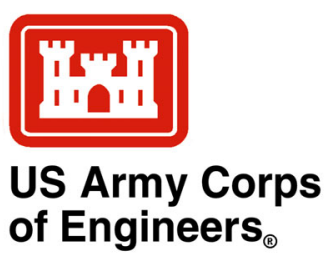

\title{
Deployment of Oceanographic Instruments in High-Energy Environments and Near Structures
}

by Philip D. Osborne, David B. Hericks, and Nicholas C. Kraus

PURPOSE: The Coastal and Hydraulics Engineering Technical Note (CHETN) herein describes methods and techniques for acquiring measurements of waves, currents and suspended sediment from high-energy wave and current environments. The case study described herein involved measurements obtained in proximity to a large jettied inlet. Two techniques are described:

a. Deployment of instrumented platforms in a high-energy surf zone.

$b$. Deployment and recovery of instrumented tripods near a submerged structure using a Sikorsky HH-60J "Jayhawk" helicopter.

BACKGROUND: High-quality field measurements are an integral part of the design process for new and existing coastal engineering projects. A key to success in modeling is a field measurement program to obtain as much information as possible about key input parameters and especially model output parameters. Calibration and verification data assist in reducing uncertainty of model output so that final results become practically useful, quantitative approximations. Carefully collected, high-resolution field measurements yield valuable insights to aid in the interpretation of processes active in a project area.

One of the major challenges in the northeastern Pacific Ocean, is to obtain field measurements when large breaking waves and strong currents are present most of the time, particularly in the surf zone and in close proximity to coastal structures such as jetties and breakwaters. Conventional methods such as SCUBA diver assistance or over-the-side vessel deployments are not feasible in such environments in terms of safety, economics and logistics. Alternative approaches including the use of helicopters (e.g., McGehee and Mayers 2000) and innovative intertidal deployment techniques have been adopted.

This CHETN describes the methods, techniques, and instrument configurations that were employed to obtain field measurements suitable for estimating sand transport rates in the surf zone and near a submerged jetty at the entrance to Grays Harbor, WA, in both winter and spring wave conditions. Grays Harbor is one of the largest estuaries in the continental United States with corresponding large tidal prism. The entrance to Grays Harbor faces the northwest Pacific Ocean and therefore experiences an extreme wave climate. Field measurements are required to determine inlet sedimentation and channel dredging requirements in the Federal navigation channel and to assess the potential benefits and impacts of sediment control measures at the North Jetty. The processes controlling sediment transport and southward bypassing at the North Jetty are complex and are spatially and temporally variable. Prior to the present study, no data 
were available on the short-term transport processes and their relationship to forcing by waves and tides in the vicinity of the North Jetty and along the adjacent beach. High resolution time series measurements of waves, currents, suspended sediment concentrations and bed levels were collected during winter and spring 2001 using a combination of helicopter-deployed tripods and innovative low-profile beach platforms that can be deployed and maintained with a minimum of two to three people. Data were collected at high frequency permitting a description of hydrodynamics and transport on time scales ranging from seconds to months.

DATA COLLECTION: Data collection included deployment of: (a) SonTek Hydra arrays to measure waves, currents, and suspended sediment concentrations (SSC) in the intertidal surf zone on North Beach, and (b) tripod-mounted Acoustic Doppler Profiler (ADP) and Hydra systems to measure waves, currents, and SSC in deeper water. In winter and spring 2001, four Hydra systems were deployed near the mean lower low water (mllw) shoreline along North Beach north of the North Jetty. The systems are referred to hereafter as Surf and Intertidal Dynamics Sensor Platforms (SIDSEP). At the same time, two ADP/Hydra systems referred to hereafter as High-Energy Sub-Tidal Tripods (HESTT) were deployed and recovered by an HH$60 \mathrm{~J}$ helicopter in deeper water. Figure 1 indicates the approximate deployment locations for the SIDSEP (OS-1, OS-2, OS-3, OS-4) and HESTT (OS-5, OS-6) platforms during the spring deployment. The SIDSEP were located at elevations from +0.3 to $-0.3 \mathrm{~m} \mathrm{(+1} \mathrm{to}-1 \mathrm{ft}) \mathrm{mllw}$ and from 80 to $140 \mathrm{~m}$ (262 to $460 \mathrm{ft}$ ) offshore of the mean higher high water (mhhw) contour $(+9.4 \mathrm{ft}$ mllw). Sta OS-5 was located north of the submerged portion of the jetty, approximately $610 \mathrm{~m}$ $(2,000 \mathrm{ft})$ offshore of the mhhw line at a bottom elevation of $-5.5 \mathrm{~m}(-18 \mathrm{ft}) \mathrm{mllw}$. Sta OS-6 was located approximately $1,040 \mathrm{~m}(3,412 \mathrm{ft})$ offshore of the mhw line at a bottom elevation of $-9.1 \mathrm{~m}(-30 \mathrm{ft}) \mathrm{mllw}$.

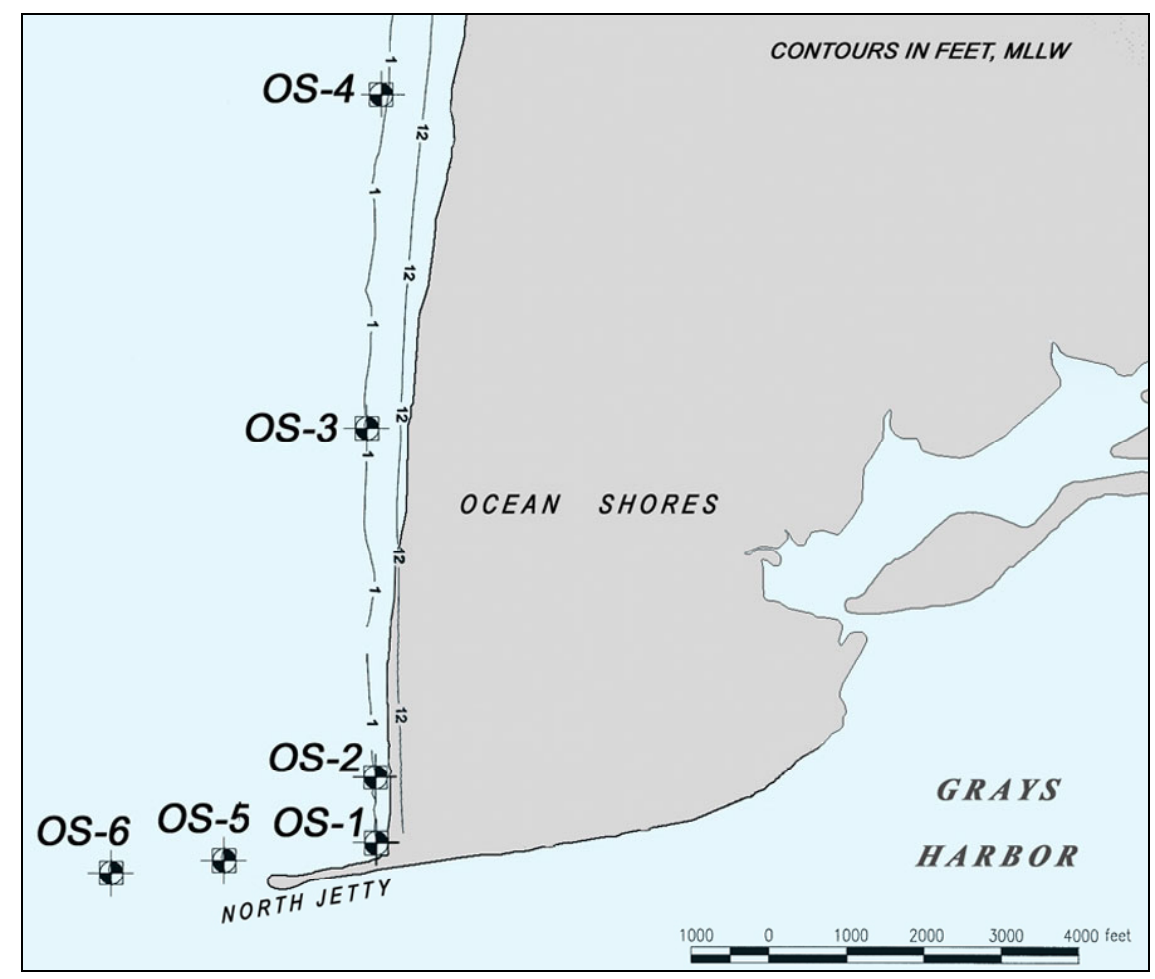

Figure 1. Instrument station locations in May 2001 deployments 


\section{Platform Design, Instrument Configuration and Deployment.}

\section{Surf and Intertidal Dynamics Sensor Platform (SIDSEP).}

The SIDSEP was designed to allow for deployment of instruments on the intertidal zone of a high-energy beach and to position the instruments above the beach surface to minimize sediment disturbance by the frame and sensors. Each platform contains a SonTek Hydra configured with a high-resolution pressure sensor, Acoustic Doppler Velocimeter Ocean (ADVO) and two optical backscattering sensors (OBS-3) (Figure 2). The combined velocity measured near the beach surface by the ADVO and suspended sediment measurements by the OBS-3 enable the calculation of suspended sediment flux. The combined measurements of the ADVO and pressure sensor enable the calculation of directional wave information.

Each SIDSEP frame is constructed of marine grade aluminum and has six 11-kg (25-lb) lead weights attached to the inside of the frame. The total frame weight, with instruments, is approximately $90 \mathrm{~kg}(200 \mathrm{lb})$ when submerged. The lead weights are sized and mounted in a manner that allows them to be easily removed, making the platform light enough to be hand carried by two people. The SIDSEP is approximately $2.1 \mathrm{~m}(7 \mathrm{ft}) \operatorname{long}, 0.6 \mathrm{~m}(2 \mathrm{ft})$ wide, and $0.6 \mathrm{~m}$ (2 ft) high (see Figure 3).

Figures 2 and 3 illustrate the position of instruments comprising the SIDSEP. The ADVO sensor, which houses the Hydra compass, was aligned horizontally to maintain a low profile, thereby maximizing submersion in the intertidal zone and to prevent the sensor sampling volume from being buried by short-term fluctuations of bed elevation that commonly occur in the swash zone. The compass and tilt sensors were positioned within the sensor head to provide correct heading, pitch, and roll data. The ADVO sensor head was protected from damage by floating debris with a cage constructed from welded stainless steel. The two OBS were mounted horizontally, inside aluminum pipe, on the sensor support upright in the same shore parallel plane as the ADVO and Paros pressure sensor. The upper OBS was located at the same elevation as the ADVO sampling volume and Paros pressure sensor.

The four SIDSEP and all equipment were tested, assembled and transported from storage, so that only minor assembly was required on the beach. After all equipment is attached to the platform a function check of all equipment was conducted.

The four SIDSEP were transported to the beach by pickup truck and placed near the mllw shoreline with a hand-pushed, four-wheeled cart (Figures 4 and 5). The cart is equipped with a differential Global Positioning System (GPS) receiver mounted on the top to accurately position the pods at predetermined locations. Battery-powered headlamps are also mounted on the cart to improve visibility when working at night (Figure 7). A 4-ft-by 2-ft-by 1-ft hole was excavated at each station by hand. When on station, the SIDSEP is lowered into the excavated hole using a 1-ton hand winch installed on the cart together with a system of pulleys. The SIDSEP was placed in the depression before backfilling with the sand removed to restore beach contours (Figure 6). Two 1.5-in. diam aluminum pipes with pointed tips were driven 3 to $4 \mathrm{ft}$ vertically into the beach and hose-clamped to the upright instrument supports for added stability. It was found that a tensioned tie-strap clipped at one end to the ADVO protective cage and at the other end to the SIDSEP frame provided additional stability to the ADVO to prevent strumming of the sensor. 
The instrument platforms were deployed during low tide, and recovered at low tide 5 days later. Personnel remained in the vicinity of the study site to periodically observe the equipment; each SIDSEP was checked at each low tide to ensure it was positioned correctly and was not in danger of being lost or buried (Figure 7). A bright orange flag with a 1.5 -m fiberglass shaft was mounted on the aluminum pipe to increase visibility of the pods and to inform surfers and swimmers of their presence while submerged.

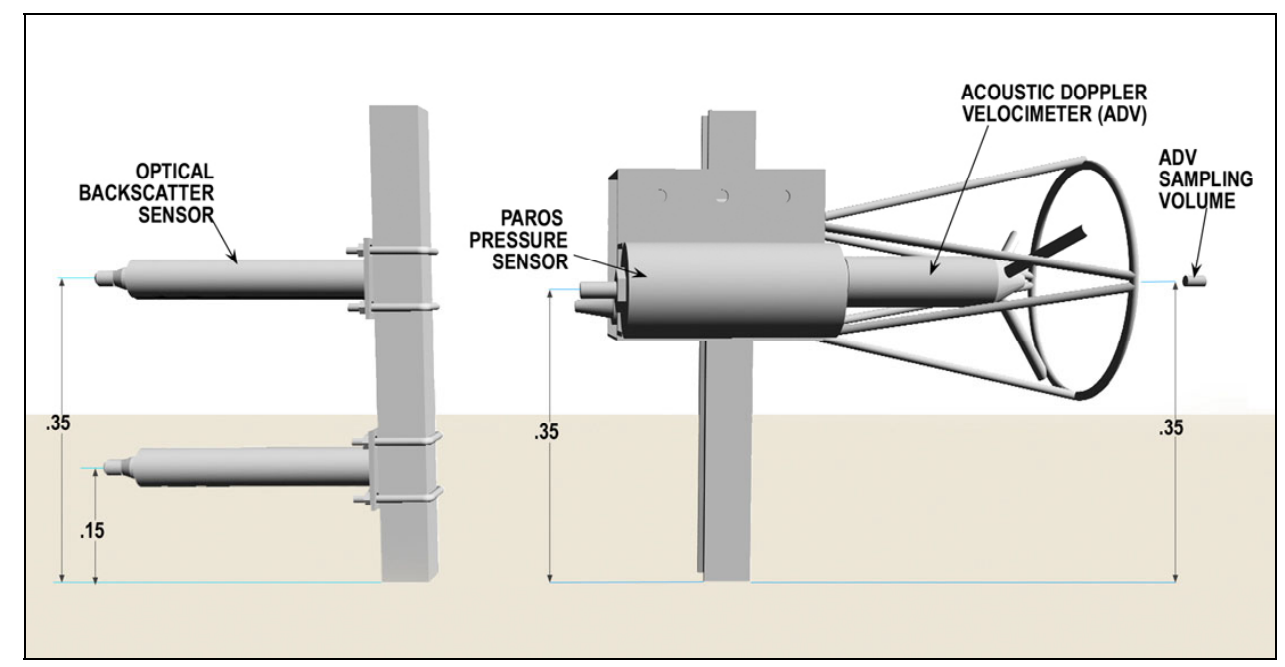

Figure 2. SIDSEP instrument configuration and nominal dimensions

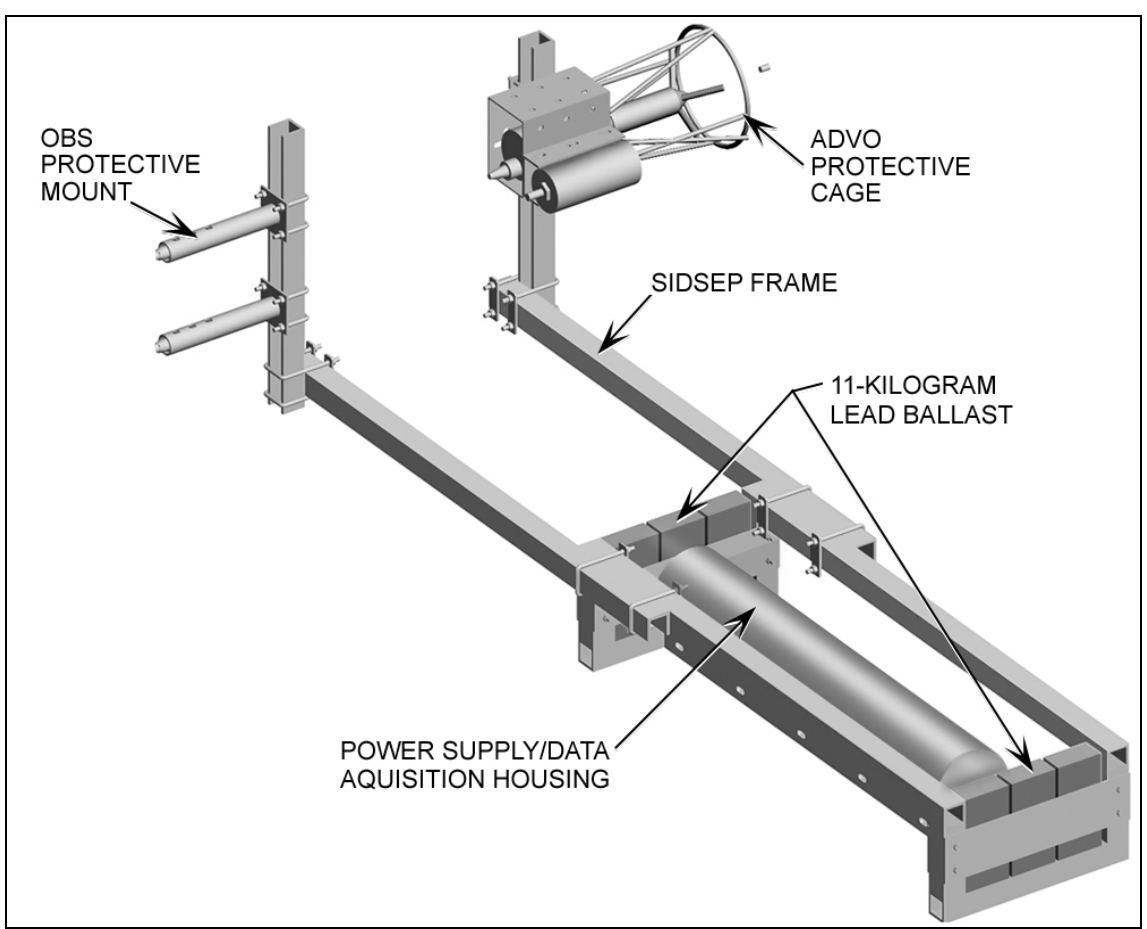

Figure 3. SIDSEP three-dimensional configuration showing instrument position relative to data logger power supply housing and lead ballast 


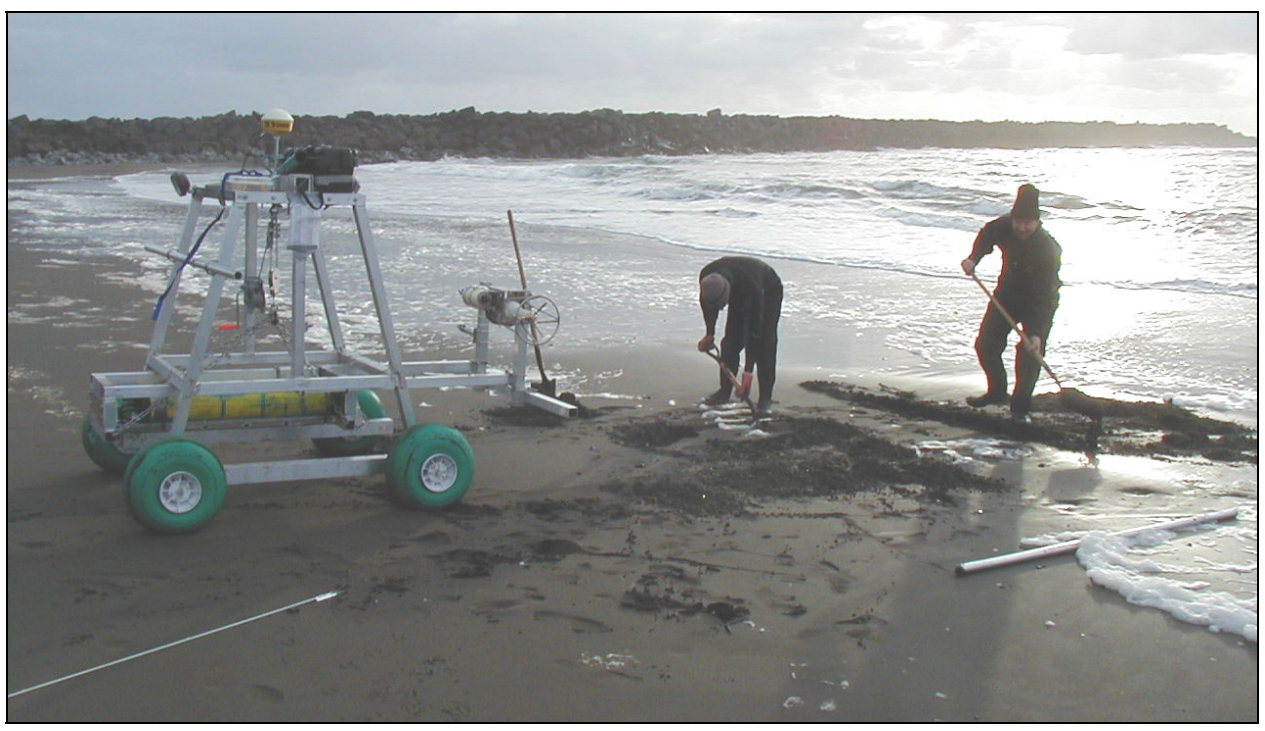

Figure 4. Preparing to deploy a SIDSEP at Ocean Shores Beach

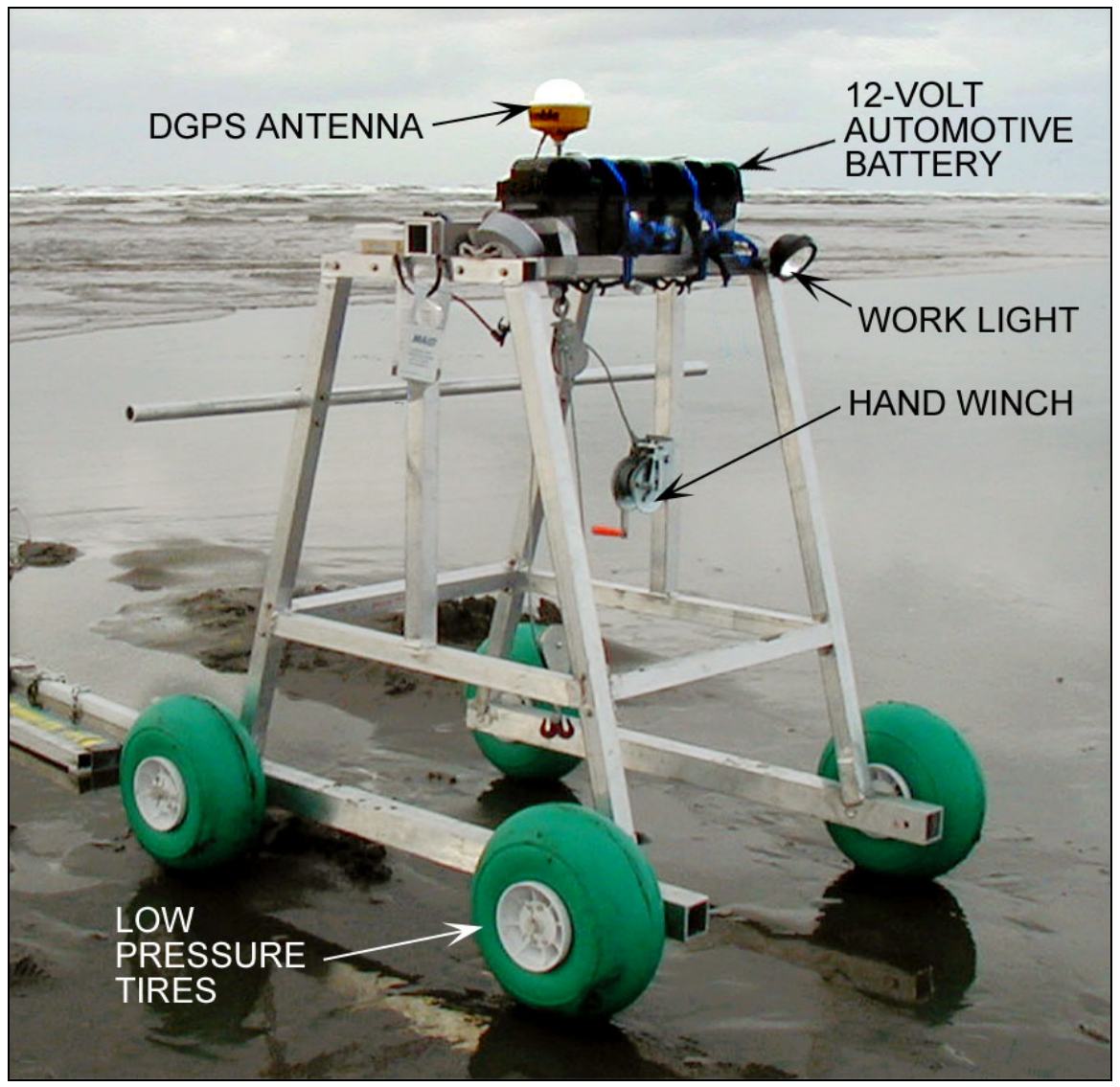

Figure 5. SIDSEP in place prior to backfilling with four-wheeled deployment cart in the foreground 


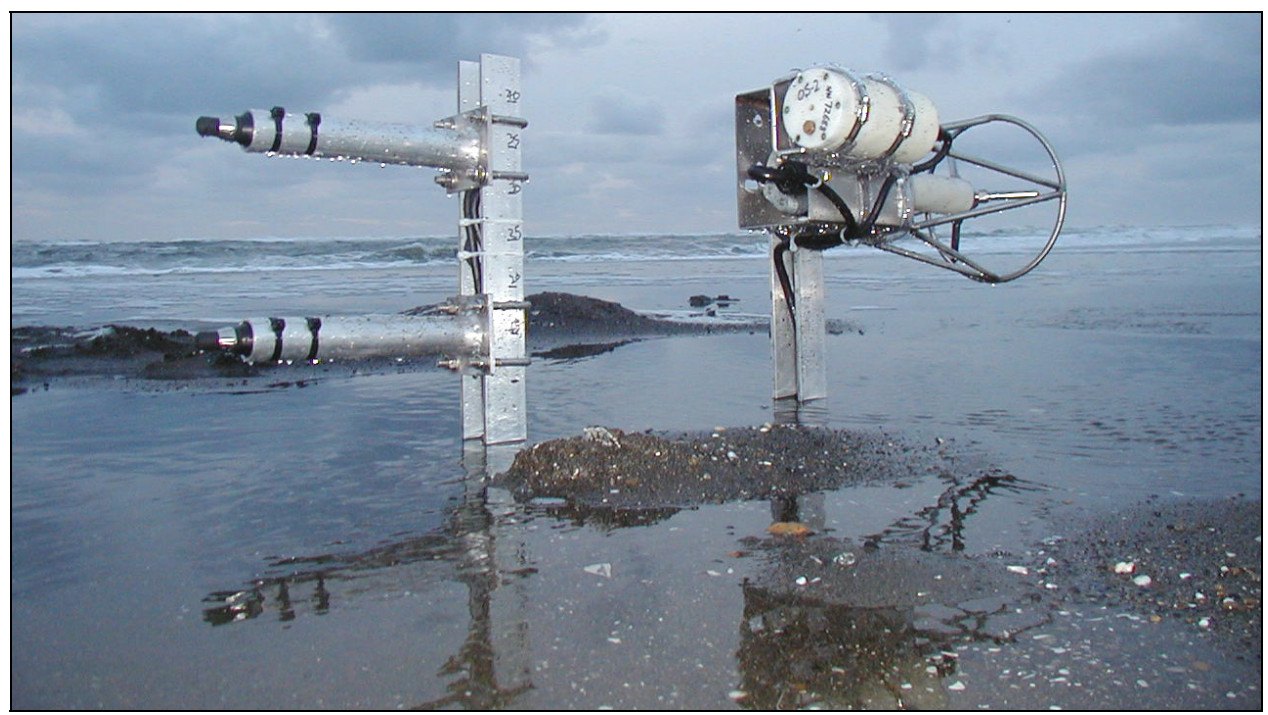

Figure 6. Sensor configuration relative to beach surface for a deployed SIDSEP

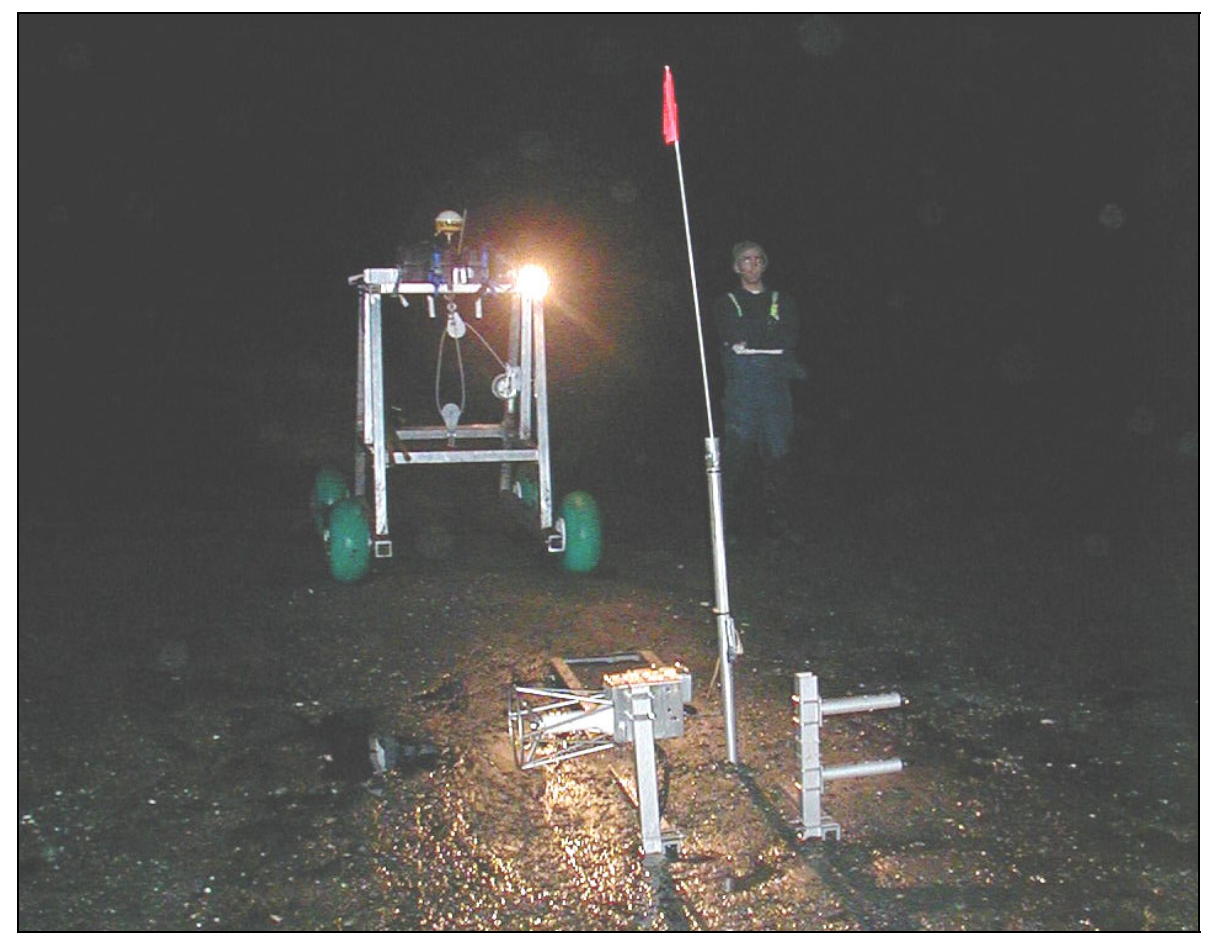

Figure 7. Inspecting a SIDSEP installation on Ocean Shores Beach at low tide

\section{High-Energy Subtidal Tripods (HESTT).}

The HESST systems were designed to be deployed and retrieved by helicopter in the high-energy wave environment at the seaward end of the North Jetty. Each of the tripods is constructed of marine grade aluminum and has eighteen $25-\mathrm{kg}(55-\mathrm{lb})$ lead weights attached to the frame. The total frame weight, with instruments, is approximately $635 \mathrm{~kg}(1,400 \mathrm{lb})$ dry weight or $550 \mathrm{~kg}$ $(1,200 \mathrm{lb})$ when submerged. Wooden feet $(50 \times 305 \times 305 \mathrm{~mm})(2 \times 12 \times 12 \mathrm{in}$.) were placed on the base of the tripod legs and attached with lag bolts (Figure 8); the feet prevent the tripods from 
sinking into the seabed and were designed to rotate and break free from the legs if buried during tripod recovery.

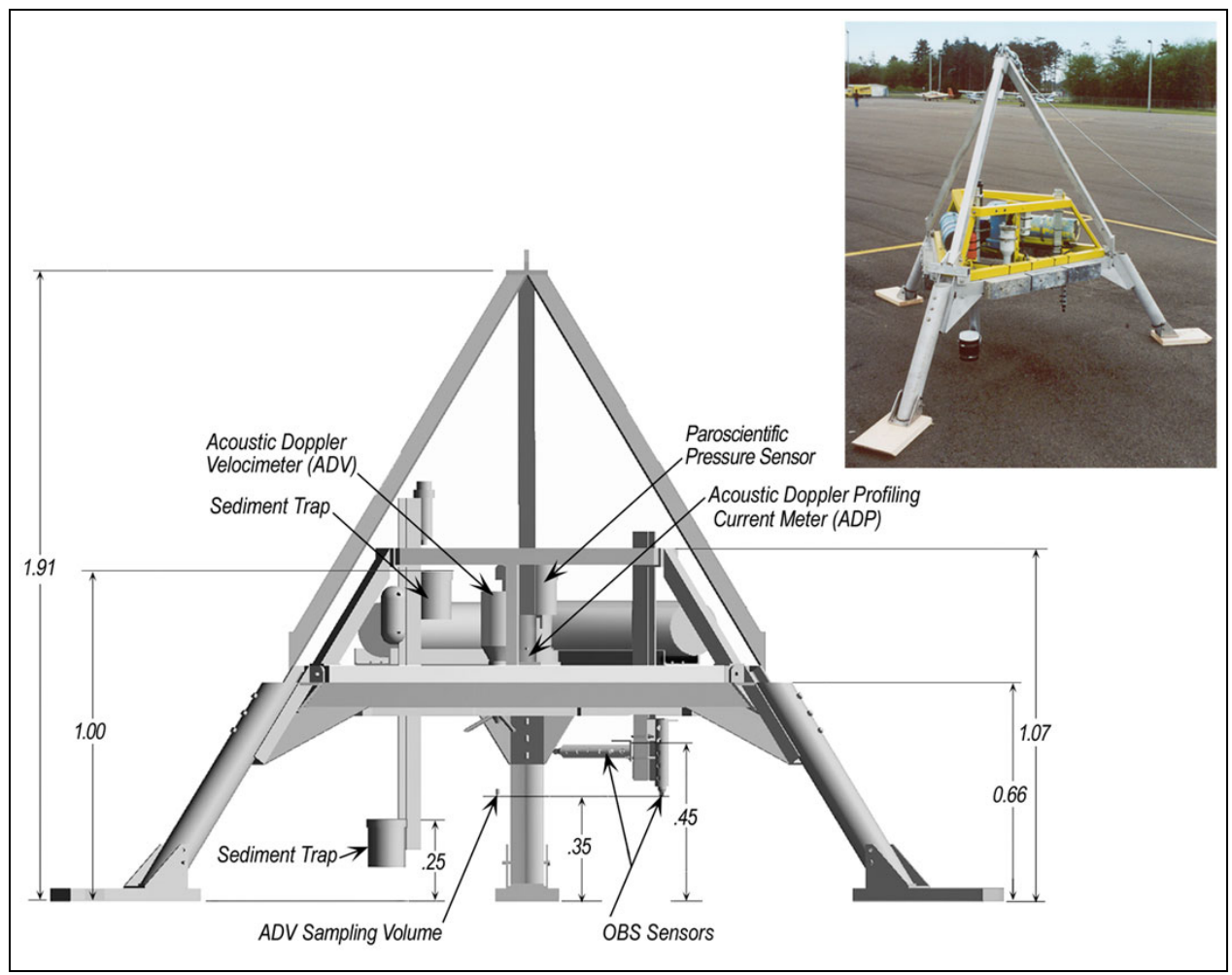

Figure 8. HESST instrument configuration and nominal dimensions

Instrumentation on the tripods consisted of a Sontek Acoustic Doppler Profiler (ADP) configured to operate at $1,500 \mathrm{kHz}$ for recording nondirectional wave data, water level, and current speed and direction through the water column in $0.5-\mathrm{m}$ bins. The tripods also contained a SonTek Hydra configured with a high-resolution pressure sensor, ADVO, and two OBS-3 sensors for recording directional wave data, water level, bottom orbital velocities, suspended sediment concentrations and bed elevations. Each tripod also supported two sediment traps for capturing suspended sediment.

The instrumentation, power supply, and data recorder housings were supported between 0.65 and $1 \mathrm{~m}$ above the base of the tripod on a detachable aluminum frame. The detachable frame was anchored to the main tripod frame using three removable bolts to allow the frame containing the instruments to be lifted free from the tripod in the event that the tripod legs became stuck in the seabed due to complete or partial burial of the tripod frame. The ADVO and OBS sensor sampling volumes and lower sediment trap were positioned in the space below the instrument support frame between elevations of 0.25 and $0.45 \mathrm{~m}$ above the nominal bed position. Sensor positions were optimized to provide useful measurements of near bed flow and suspended sediment load while at the same time attempting to minimize chances for burial and avoiding interference to flow and suspension by the tripod legs or frame. The ADP was mounted centrally in the instrument support frame with the transducer surfaces at a nominal elevation of $1 \mathrm{~m}$ above 
the base of the tripod. The ADP transducers were oriented to avoid interference to the acoustic beams by the tripod legs.

The tripods were partially assembled and transported to the airport nearest the field site by box truck for final assembly and deployment by helicopter. The method and hardware for deploying and recovering the tripods essentially follows that outlined by McGehee and Mayers (2000) with a few minor modifications and improvements for use of a Sikorsky HH-60J "Jayhawk" helicopter (Figures 9 and 10).

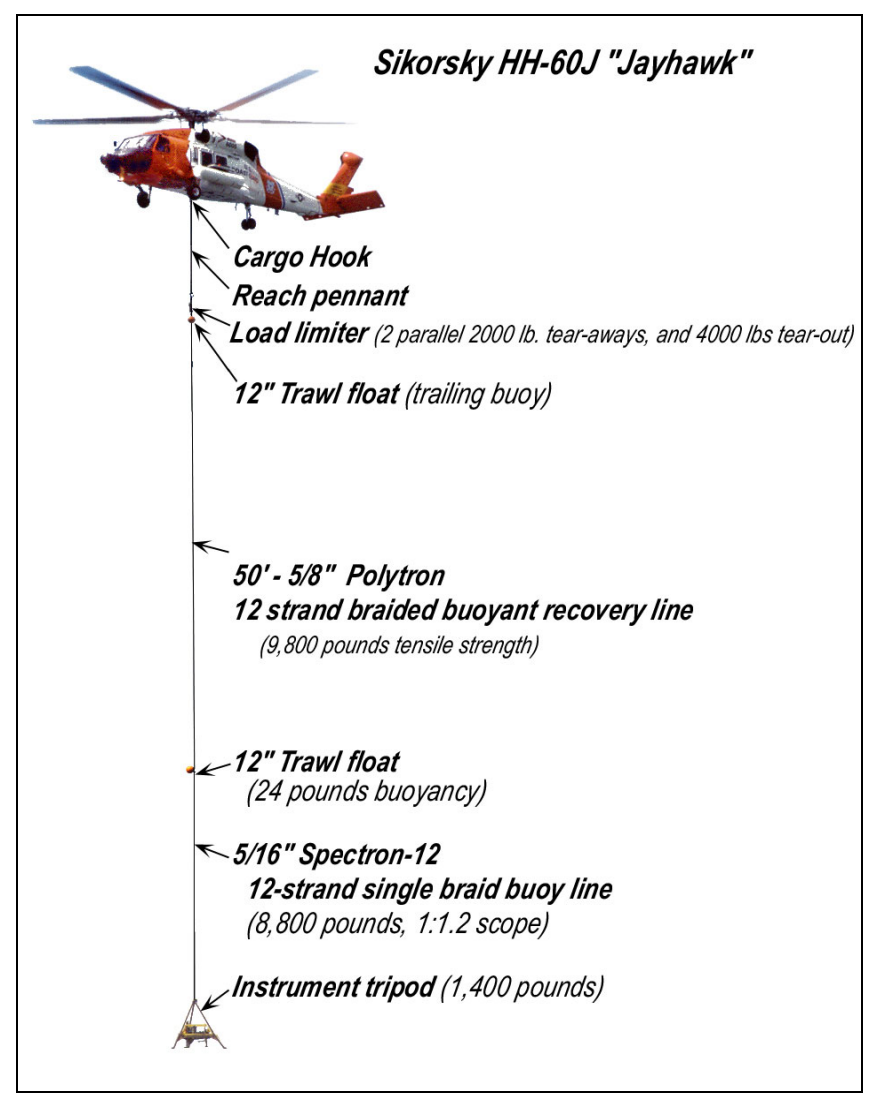

Figure 9. Principal components of the helicopter tripod deployment/recovery system

Assistance was requested from the U.S. Coast Guard Air Station Astoria because personnel there had familiarity with the deployment site and prior experience with oceanographic instrument deployments on the Oregon coast (e.g., Pollock 1995). Advantages of the HH-60J are its capability to remain airborne for durations up to $7 \mathrm{hr}$, a 6,000-lb lift capacity, a cargo hook and rescue hoist, and a Rockwell-Collins HFCS-8000 automated flight management system that integrates all of the helicopter's communications and navigation equipment. The pilot can program the autopilot to fly to a predetermined location automatically, freeing the pilot and copilot to assist in visual observation of the deployment operation. In addition, this system can

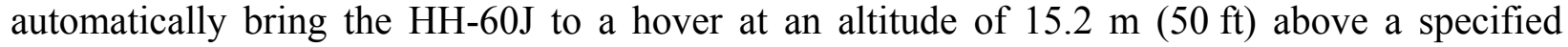
location. This feature is especially useful in rough weather for the purpose of locating and relocating deployed instruments. 

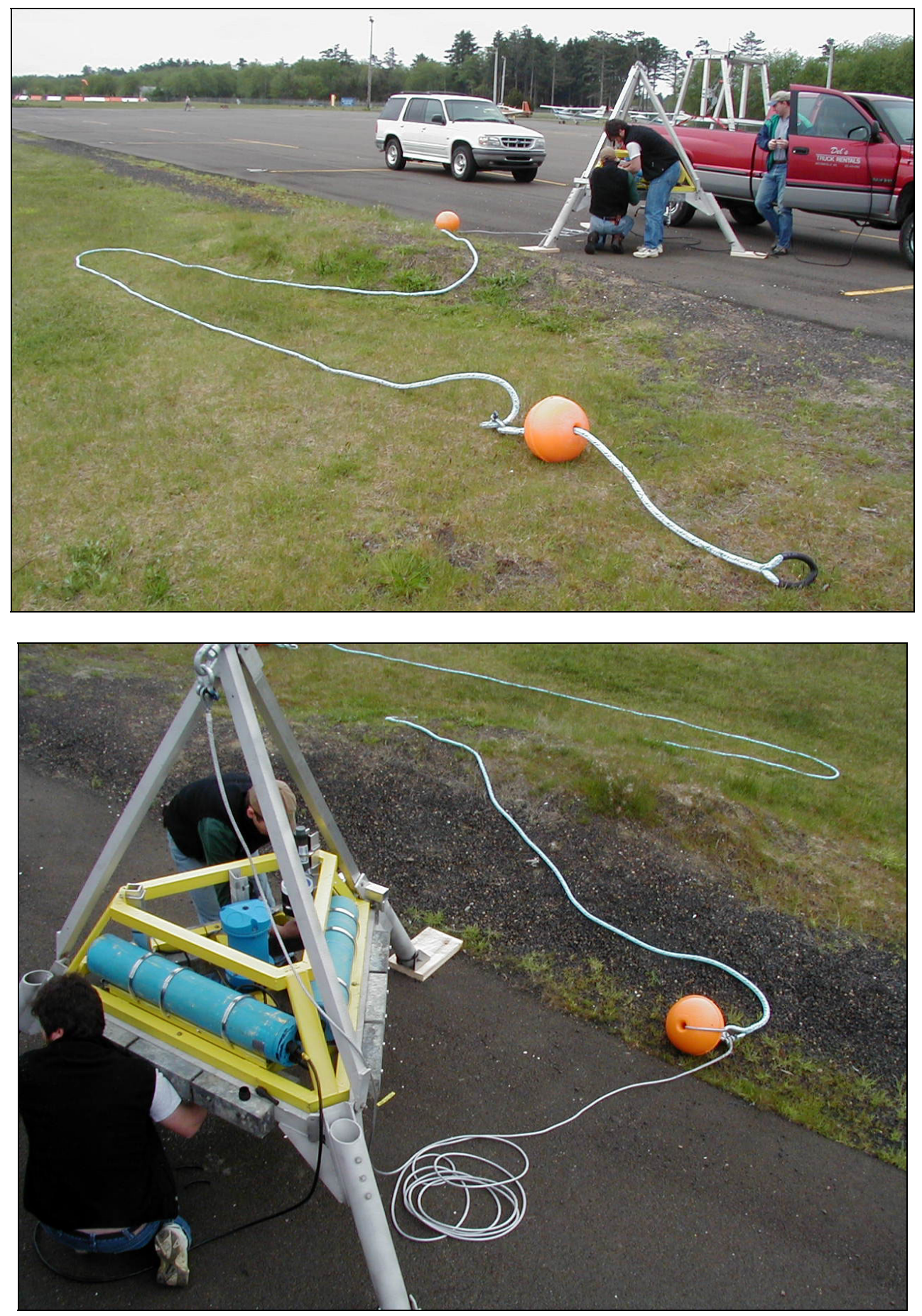

Figure 10. HESST platforms and buoy line assembly in final stages of preparation before deployment

The principal components of the deployment/recovery system consist of the instrument tripod, a buoy line, a 304-mm (12-in.)-diam trawl float with 11-kg (24-lb buoyancy), a 50-ft -buoyant recovery line with a 304-mm (12-in.) diam, trailing trawl float, a grapnel, the helicopter rescue hoist, a reach pennant and a load limiter system (Figures 9 and 10). The drag and floatation of 
the line and buoy components were modeled with the Mooring Design and Dynamics Package Version 1.06 developed in MATLAB 5.2 (Dewey 1998). The programs can evaluate and optimize surface and subsurface components (lengths and materials) of a mooring system and their response to current drag. The models predicted if the recovery line would float under strong current conditions and if the drag on the line would contribute significantly to overturning of the platform. The instrument pods were deployed and recovered at high tide near slack to avoid unnecessary drag on the recovery and buoy lines during deployment and recovery.

Buoy line. The buoy line is $5 / 16$ in. diam Spectron ${ }^{\mathrm{TM}}-12$, a 12 -strand single braid line with $4,000-\mathrm{kg}(8,800-\mathrm{lb})$ tensile strength. This small diameter specialized line was chosen to minimize drag and reduce the likelihood of the tripod overturning during strong currents. The buoy line lengths were set at 1.2 times the expected maximum water depths of $35 \mathrm{ft}$ and $42 \mathrm{ft}$ for sta OS-5 and OS-6, respectively. The buoy lines were backspliced with galvanized thimble and connected to the apex of the tripod with a 5/8-in. shackle and a 5/8-in. swivel shackle. All hardware components of the buoy line assembly were designed with a minimum 6,000-lb breaking strength. The lines were selected to accommodate approximately 150 percent of the design load when new to allow for chafing or deterioration during the month-long deployment. All lines were of braided construction as twisted-strand lines could unravel and spin the platform while suspended under the helicopter.

Recovery line. The recovery line is a 50 -ft length of $5 / 8$-in. Polytron 12 -strand braided buoyant line with tensile strength of $4,445 \mathrm{~kg}(9,800 \mathrm{lb})$ and specific gravity of 0.94 . A soft eye is backspliced in the top end and reinforced with rubber tubing. During deployment the eye of the buoyant recovery line was attached directly to the cargo hook on the HH-60J and flown to the deployment site. The assembly was then lowered until slack appeared in the buoyant line, indicating the tripod was in position on the sea bottom. The pilot then released the buoyant line from the cargo hook.

During recovery, the floating line was approached perpendicularly with the grappling hook just below the water surface. Continuing forward and upward the floating line was picked up by the grappling hook, the trailing buoy providing a stop if required. The buoyant line was then lifted to the helicopter using the helicopter's rescue hoist system (Figure 11); load limiters and a reach pennant were attached to the end of the buoyant line and the free end placed manually on the cargo hook by means of the reach pennant. As the helicopter slowly gained altitude and the load was taken on the line, the load limiters were observed for tearing until the platform was free of the bottom and any sand burial that had occurred. Once the platform was clear of the water surface and at a safe altitude, the helicopter followed a predetermined flight path over water and unpopulated terrain back to the local airport.

Load limiters. A significant safety issue associated with this type of helicopter deployment is the potential failure of a line under load, which could recoil into the helicopter rotor blades. The load limiter system was integrated as a safety measure to prevent dynamic or static loads from exceeding the design strength $(6,000 \mathrm{lb})$ of the recovery assembly with an added safety factor. This might have been the case had the tripods been deeply buried by sediment. The load limiters were made from two parallel "tear-aways," each with 2,000-lb capacity giving an effective $4,000-1 b$ capacity of the recovery system. If the load capacity is exceeded, the tearing of the 
apparatus can be observed and the load released before any components fail. This weak link is placed into the lifting system during recovery, rather than being part of the deployed components, so it can be inspected prior to use. Placing the weakest component at the top of the recovery line can cause the line to recoil away from the helicopter in the event of failure.

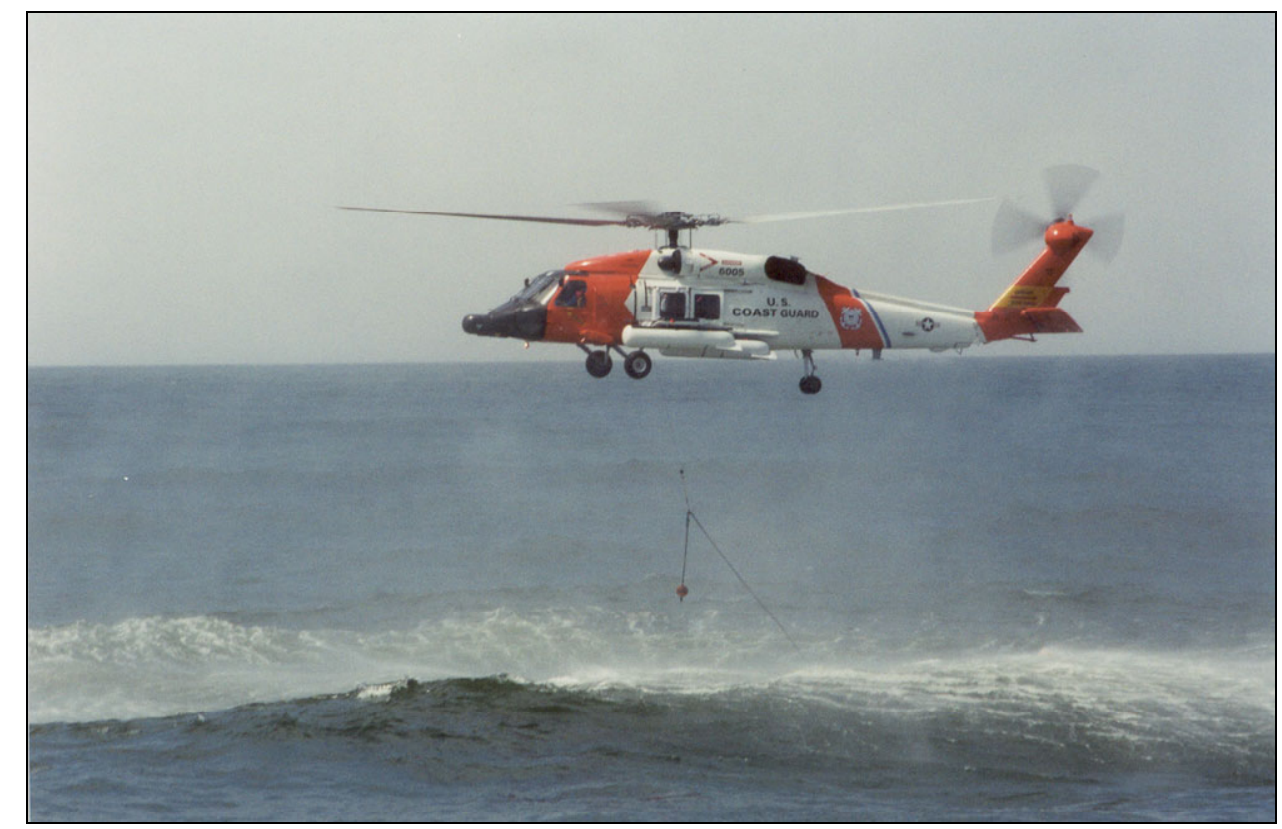

Figure 11. HH-60J helicopter (USCG Air Station Astoria) retrieving buoyant line and trailing float from the surface with a grapnel at sta OS-5 (May 30, 2001)

ADDITIONAL INFORMATION: This technical note was produced under the Grays Harbor, Washington, Operation and Maintenance North Jetty Study - "Evaluation of Functional Performance of Coastal Spur Dike and Identification of Alternatives" directed by Dr. Nicholas C. Kraus at the U.S. Army Engineer Research and Development Center, Coastal and Hydraulics Laboratory, in collaboration with activities of the Coastal Inlets Research Program (CIRP). Questions about this technical note can be addressed to Dr. Philip D. Osborne at philo@piengr.com or by telephone at (425) 921 1720, David B. Hericks at davidh@piengr.com (phone: 425-921-1704), or Dr. Kraus at Nicholas.C.Kraus@erdc.usace.army.mil (telephone (601) 634-2016). For further information about the Grays Harbor study or the CIRP, please consult the Web site http://chl.wes.army.mil/research/cprocesses/grays/ or contact Dr. Kraus. This CHETN should be cited as follows:

Osborne, P. D., Hericks, D. B., and Kraus, N. C. (2002). "Deployment of oceanographic instruments in high energy environments," ERDC/CHL CHETNIV-46, U.S. Army Engineer Research and Development Center, Vicksburg, MS. http://chl.wes.army.mil/library/publications/chetn 


\section{REFERENCES}

Dewey, R. K. (1998). "Mooring design and dynamics package, Version 1.06.” http://canuck.seos.uvic.ca/rkd/mooring/moordyn.html

McGehee, D., and Mayers, C. J. (2000). "Deploying and recovering marine instruments with a helicopter," ERDC/CHL CHETN-VI-34, U.S. Army Engineer Research and Development Center, Vicksburg, MS. (http://chl.wes.army.mil/library/publications/chetn).

Pollock, C. E. (1995). "Effectiveness of spur jetties at Siuslaw River, Oregon, Report 2, localized current flow patterns induced by spur jetties: Airborne current measurement system and prototype/physical model correlation,” Technical Report CERC-95-14, U.S. Army Engineer Waterways Experiment Station, Vicksburg, MS. 